\title{
The Almond plumage color pattern is associated with eye pigmentation defects in the domestic pigeon (Columba livia)
}

Rebecca Bruders ${ }^{1}$, Max Sidesingerr ${ }^{1}$, Michael D. Shapiro ${ }^{1, *}$

${ }^{1}$ School of Biological Sciences, University of Utah, Salt Lake City, Utah, United States of America

${ }^{*}$ Corresponding author

Email:mike.shapiro@utah.edu 


\section{Abstract}

Changes in epidermal pigmentation are associated with eye defects in humans and other

3 vertebrates. In the rock pigeon (Columba livia), the sex-linked Almond color pattern is

4 characterized by hypopigmentation of epidermal structures. The trait is controlled by the classical

5 Stipper (St) locus, and homozygous $\left(\mathrm{Z}^{S t} \mathrm{Z}^{S t}\right)$ Almond males often have severe eye defects.

6 Heterozygous $\left(\mathrm{Z}^{S t} \mathrm{Z}^{+}\right)$and hemizygous $\left(\mathrm{Z}^{S t} \mathrm{~W}\right)$ pigeons do not typically have obvious eye defects,

7 suggesting that higher dosage of the mutant allele is deleterious. Because Almond pigeons have

8 pronounced hypopigmentation in epidermal structures, we hypothesized that they might also have

9 reduced eye pigmentation. Here, we examined pigmentation in the iris, ciliary body, anterior

10 retinal pigmented epithelium (RPE), and posterior RPE in pigeons with and without Almond

11 alleles. We found that pigmentation of anterior segment structures was reduced in birds with at

12 least one Almond allele. However, posterior eye pigmentation was substantially reduced only in

13 homozygous Almond birds. We postulate that the gradient of effects on eye pigmentation is due

14 to the different embryological origins of anterior and posterior eye pigment-producing cells. 


\section{Introduction}

Eye defects are linked with changes in epidermal pigmentation in a variety of vertebrate

17 species [1-5]. This link is driven in part by shared mechanisms that regulate development of

18 pigment in both the eye and epidermis, including appendages such as feathers, scales, and hairs.

19 Melanin-producing cells synthesize pigment granules in specialized organelles called

20 melanosomes, which are exported to cells in the eye and skin [6,7]. As a consequence of the

21 common organellar origins of eye and skin melanins, mutations in genes important for

22 melanosome function can lead to melanin-based pigmentation defects in both eyes and epidermal

23 derivatives. For example, in humans, mutations in several genes involved in pigmentation are

24 associated with oculocutaneous albinism (OCA), a group of inherited diseases that affect eye,

25 skin, and hair pigmentation [5, 8-12]. In mice and zebrafish, mutations in melanosome genes

26 such as $S l c 24 a 5, R a b 38$, and $O c a 2$ can result in pigmentation changes in both the eye and

epidermal tissues that are phenotypically similar to OCA in humans [1, 13-15].

In addition to OCA-like syndromes, other mutations have linked effects on pigmentation

of the eye, epidermis, and epidermal appendages. Dogs that are heterozygous for a mutation in

pmel (a gene that encodes a melanosome structural protein) have a patchwork Merle coat color

31 pattern. However, homozygous Merle dogs have a dramatic reduction in coat pigmentation and

32 show variable eye defects, including microphthalmia, iris coloboma, and cataracts [16, 17].

Pigment development in the eye and epidermis has both shared and distinct

34 characteristics, which probably explains the spectrum of shared and distinct effects of mutations

35 on eye and epidermal phenotypes. Most epidermal pigmentation comes from melanin-producing

36 cells called melanocytes. Melanocytes are neural crest-derived cells that produce pigment-loaded

37 melanosomes $[18,19]$, which are subsequently transferred to the skin and its appendages [20]. In 
contrast, eye pigmentation originates from two distinct cell populations, melanocytes and pigmented epithelial cells. The latter population originates from optic cup neuroepithelium instead of neural crest [7, 19-21].

In the eye, melanosome-containing structures include the iris pigmented epithelium (IPE), ciliary body, and retinal pigment epithelium (RPE) (Fig 1). Pigmentation is protective against cellular oxidative damage due to UV radiation, yet pigmentation is not directly necessary for normal functions of eye structures [22-24]. The anterior structures of the eye (ciliary body and IPE) receive melanosomes that come from both the neural crest and optic cup neuroepithelium [7, 19-21]. However, the RPE of the posterior compartment of the eye receives pigmented melanosomes from only the optic cup neuroepithelium. While both types of cells produce melanosomes, neural crest cell-derived melanocytes and optic cup neuroepitheliumderived RPE cells sometimes respond differently to mutations in pigmentation genes. For example, in Dominant white chickens, mutations in PMEL17 (Pmel ortholog) result in a lack of pigmentation in feathers and choroidal melanocytes (derived from neural crest cells), but RPE pigmentation is unaffected [25]. Additionally, mutations in the transcription factor gene Mitf, a "master regulator" of pigment development, can cause a lack of pigment in neural crest or optic cup derivatives - but not necessarily both - due to cell-type specific isoforms of Mitf $[7,26]$. Finally, more than 150 genes are involved in epidermis and epidermal appendage pigmentation in laboratory mice, and some of these mutations affect eye development, while others do not [27]. The partially overlapping developmental origins of epidermal and eye pigmentation provide a general explanation for why some mutations might only lead to skin changes, while others induce differences in both organs.

In the domestic pigeon, Almond feather pattern is a variegated pattern of hypopigmented 
61 and heavily pigmented feathers that is also linked with eye defects. Almond is a sex-linked trait

62 controlled by the $S t$ locus, in which hemizygous Almond females (ZW sex chromosomes) and

63 heterozygous Almond males (ZZ) have changes in feather pigmentation that create a sprinkled

64 pattern, but do not have known eye defects. However, homozygous Almond males typically have

65 severe feather hypopigmentation and eye defects [28-30] described as "bulging bladder eyes" or

66 "pop-eyes" [31-35] with "dark and irregular pupils" (coloboma) [34] or lens-absent eyes [32].

Previously, we identified a 359-kb candidate region for Almond on the Z-chromosome

68 [36]. This region contains eight annotated protein-coding genes, none of which have fixed

69 coding changes in Almond birds. However, we found that Almond genomes have a complex

70 copy number variant in the candidate region that contains two full-length genes, Mlana and

71 Slc16a13. Both genes have expression changes in the regenerating feather buds of Almond

72 compared to non-Almond birds. Mlana is involved in melanosome development, and it interacts

73 with Pmel to form complexes in the endoplasmic reticulum, trans-Golgi network, and stage I

74 melanosomes [37, 38]. Mutations in Pmel are linked to eye, epidermis, and epidermal appendage

75 pigmentation defects in numerous animals [16, 17, 25, 39-49]. In contrast, Slc16a13 does not

76 have a known role in pigmentation, and the function of this gene is poorly understood beyond its

77 genomic association with type 2 diabetes [50-55]. We therefore proposed Mlana as a strong

78 candidate gene for Almond [36].

80 plumage variation is linked to eye pigmentation changes remains unknown. Therefore, we

81 performed a histologic study of eyes of pigeons with and without Almond alleles. Specifically,

82 we quantified pigment content in the RPE, ciliary body, and iris to test for eye pigmentation

83 changes associated with Almond genotypes. 


\section{Results}

\section{Iris}

All eyes from pigeons with Almond genotypes had less pigmentation than non-Almonds

88 in the iris, the most anterior structure we measured (Fig $1 \mathrm{~A}$ and $2 \mathrm{~A}$; Anova, $\mathrm{p}=2.2 \times 10^{-7}$; post-

89 hoc Tukey, $\mathrm{p}<0.05$ for all Almond genotypes). Homozygous Almonds had a mean of $1.0 \%$ of

90 the iris pigmented, compared to $51.2 \%$ in birds without Almond alleles (post-hoc Tukey, $\mathrm{p}=3.0$

$\left.91 \times 10^{-7}\right)$. Heterozygotes and hemizygotes were more pigmented than homozygotes $(9.2 \%$ and

$929.7 \%$, respectively), but the differences among genotypes were not significant (post-hoc Tukey, $p$

$93>0.05)$.

\section{Ciliary body}

In the ciliary body, all Almond genotypes were less pigmented than non-Almonds (Fig

97 3A and 3B; Anova, $\mathrm{p}=1.5 \times 10^{-8}$, post-hoc Tukey, $\left.\mathrm{p}>0.05\right)$. Similar to the iris, the ciliary body

98 had the highest mean pigmented area in non-Almond eyes (33.1\%), and the lowest in

99 homozygous Almond eyes $(2.4 \%$, Fig 3A; post-hoc Tukey, $\mathrm{p}=0)$. Hemizygotes were slightly

100 more pigmented than homozygotes with a mean of $6.4 \%$ pigmentation (post-hoc Tukey, $\mathrm{p}>$

101 0.05). Heterozygotes had the most pigmentation of the Almond genotypes $(9.7 \%$, significantly

102 higher than homozygous Almond; post-hoc Tukey, $\mathrm{p}=0.019$ ).

103

104 Anterior RPE

Anterior RPE pigmentation was measured at the ora serrata, a landmark that can be 
106 reliably identified because of its distinct morphology (Fig 1C). The anterior RPE of all Almond

107 genotypes had significantly less pigmented area compared to non-Almonds (Fig 4A and 4B;

108 Anova, $\mathrm{p}=1.4 \times 10^{-4}$; post-hoc Tukey, $\left.\mathrm{p}>0.05\right)$. Non-Almond eyes had a mean of 51.9\%

109 pigmentation in the anterior RPE, while heterozygous, hemizygous, and homozygous eyes had

110 means of $28.1 \%, 19.2 \%$, and $5.7 \%$, respectively. The anterior RPE was significantly less

111 pigmented in homozygotes than in heterozygotes (post-hoc Tukey, $\mathrm{p}=0.03$ ).

113 Posterior RPE

The posterior RPE (Fig 1D) adjacent to the optic nerve - the most posterior eye structure

115 measured - had smaller pigmentation differences among genotypes than other regions. Non-

116 Almond, heterozygous Almond, and hemizygous Almond genotypes were similar to each other

117 with mean pigmented areas of $66.0 \%, 53.3 \%$, and $56.2 \%$, respectively (post-hoc Tukey, p $>0.05$;

118 Fig 5A). Only homozygous Almonds had significantly less pigment than non-Almonds with a

119 mean pigmented area of $35.9 \%$ (Fig 5A and 5B; Anova, $p=0.01$; post-hoc Tukey, $p=0.0064$ ).

\section{Pigment-containing cell layers}

By gross visual examination, all histologic sections of all genotypes appeared to retain

123 the epithelial layer that contains pigment in non-Almond birds. Even in homozygous Almond

124 hatchlings, which showed the least amount of pigmentation in all eye regions, this layer also did

125 not have any obvious morphological changes compared to non-Almond.

126 In summary, all of the Almond genotypes had significant decreases in pigmentation in

127 anterior structures, especially in the iris and ciliary body, the two most anterior structures. In 
128 contrast, pigmentation in the posterior RPE was significantly lower only in homozygous Almond 129 eyes.

\section{Discussion}

\section{Almond alleles cause more anterior than posterior depigmentation}

In the eyes of hatchling pigeons with one or two Almond alleles, anterior structures had

greater reductions in pigmentation than did posterior structures. A potential explanation for these

135 disparities is the different developmental origins of melanin-depositing cells in different

136 segments of the eye. In the posterior RPE, pigment is deposited by cells of the optic cup

137 neuroepithelium [20]. In anterior eye structures, including the iris and ciliary body, pigment

138 comes from both the neural crest-derived melanocytes and cells that originate from the optic cup

139 neuroepithelium [7]. In birds with Almond alleles, we found that structures receiving pigment

140 from both sources were less pigmented than those receiving pigment from the neuroepithelium

141 alone. Therefore, neural crest-derived pigmentation of the eye is more severely affected than

142 neuroepithelium-derived pigmentation. Similarly, feather pigmentation is deposited by neural

143 crest-derived melanocytes, and plumage color is severely affected in birds with Almond alleles.

144 Thus, Almond-linked pigmentation changes in the anterior segment of the eye and the epidermis

145 share a common cellular origin, the neural crest.

146 In the posterior RPE, we saw a significant but relatively modest pigmentation reduction

147 in homozygous Almond eyes relative to all other genotypes. This situation is analogous to what

148 is observed in the plumage: hemizygous and heterozygous Almond pigeons have reduced (but

149 still plentiful) feather pigmentation, but homozygotes lose almost all plumage pigmentation [36].

150 In developing homozygous feathers, but not in other genotypes, we saw a collapse of the 
151 pigment synthesis gene expression pathway. We do not have comparable gene expression data

152 for eye structures, but we speculate that a similarly broad set of pigment synthesis changes

153 impact all pigment-producing cells, not just those derived from the neural crest. Overall, in both

154 the feathers and eyes of Almond pigeons, we see a dosage effect wherein two Almond alleles

155 cause a more severe pigmentation phenotype than one. For reasons that we do not yet

156 understand, anterior eye pigment deposition is more sensitive to this dosage effect than posterior

157 deposition. Melanocytes are migratory and encounter dynamic cellular surroundings as they

158 move toward their destination, whereas RPE cells have a more stable tissue microenvironment;

159 perhaps these contextual differences contribute to differential resiliency of pigment cell

160 development and function [7].

162 Homozygous Almond eyes have both pigmentation and structural

163 defects

Homozygous Almond eyes had the least pigmentation of any genotype. In the most

165 anterior regions, the iris and ciliary body, almost no pigment was visible (Fig $2 \mathrm{~B}$ and 3B).

166 Homozygous Almond was also the only genotype with significantly reduced pigmentation in the

167 posterior RPE (Fig 5A and 5B). It remains unclear if and how a paucity of melanin is

168 mechanistically linked to other structural developmental defects such as bulging "pop-eyes",

169 colobomas, and the absence of lenses [31-35]. Neural crest cells are the progenitors of

170 melanocytes and other structures that comprise the anterior segment of the eye [7, 56-58].

171 Hence, if the Almond mutation specifically affects neural crest-derived structures, then it could

172 lead to the anterior segment defects observed in homozygous Almond pigeons. A related

173 possibility is that pigment deposition could be necessary for the normal development of anterior 
174 segment structures. Signaling between tissue layers of the eye is necessary for proper

175 development [59]. Therefore, defects in anterior pigmented structures could, in turn, lead to

176 bulging or malformed corneas, as well as lens and eyelid defects.

Another potential route to eye structural defects is the "leaking" of toxic pigment cell

178 components. In humans, pigmentary glaucoma (PG) and pigment dispersal syndrome (PDS)

179 affect anterior eye structures and are sometimes associated with mutations in PMEL [60]. PMEL

180 is critical for melanosome maturation and physically interacts with MLANA [38], a protein that

181 is encoded in the Almond genomic candidate region of pigeons [36]. In cases of PDS, pigment

182 disperses from the iris to surrounding tissues and induces other defects, such as increased ocular

183 pressure and corneal endothelial pigment deposition [61]. However, both PDS and PG generally

184 do not affect lens development, which precedes pigment deposition.

\section{Lessons from melanosome defects in other animals}

several animal species. In some cases, the genes responsible for these linked defects are involved

191 pigmentation and eye or vision defects in several species. Pmel encodes an amyloid structural

192 protein that contributes to the melanosome matrix $[65,66]$. Pmel interacts directly with Mlana, a

193 top candidate gene for Almond in pigeons, during melanosome maturation [38].

195 defects, and their phenotypes are often qualitatively similar to Almond pigeons. In zebrafish, loss

196 of function in one pmel paralog (pmela) leads to a reduction in pigment in the body and eye, and 
197 also enlarged anterior eye segments, likely due to increased intraocular pressure [60]. Similarly,

198 some homozygous Almond pigeons also appear to have enlarged anterior segments [30, 69, 70,

199 personal observations]. Other Pmel mutants, including silver horses [48, 68, 69] and

200 homozygous Merle dogs [16, 17, 43, 70], also have associated defects in anterior eye structures.

201 A counterexample of this trend is the PMEL17 Dominant white mutation in chickens, which

202 results in the loss of epidermal feather pigmentation but is not associated with changes in eye

203 pigmentation [25].

204 Based on our findings of an anterior-posterior pigmentation gradient in Almond pigeon

205 eyes, we are interested to test whether eye pigmentation disparities in other species track with

206 embryological origins of pigment cells. For example, we predict that pmel mutants with

207 epidermal and anterior eye structural defects, such as Merle dogs and silver horses, might have

208 anterior-posterior gradients of eye pigmentation defects that are similar to what we observe in

209 Almond pigeons.

210

\section{Materials and Methods}

\section{Ethics statement}

213 Animal husbandry and experimental procedures were performed in accordance with

214 protocols approved by the University of Utah Institutional Animal Care and Use Committee

215 (protocols 10-05007, 13-04012, and 16-03010).

216

\section{Sample collection}

218 Offspring from crosses of heterozygous Almond males $\left(Z^{S t} / Z^{+}\right)$and Almond females 
$219\left(\mathrm{Z}^{\mathrm{St}} / \mathrm{W}\right)$ were euthanized within $8 \mathrm{hr}$ of hatching. Whole eyes were collected and fixed overnight

220 in 4\% paraformaldehyde, then preserved in 70\% ethanol. Eye samples for 4 individuals of each

221 genotype (non-Almond, hemizygous Almond, heterozygous Almond, and homozygous Almond)

222 were then embedded in paraffin and sagittally sectioned to a thickness of $8 \mu \mathrm{m}$ by ARUP

223 Laboratories (Salt Lake City, UT).

\section{Genotyping of Hatchlings}

Brain tissue was collected at the same time as each eye sample and stored at $-80^{\circ} \mathrm{C}$ for

227 DNA extraction and genotyping. We extracted DNA using the Qiagen DNeasy Blood \& Tissue

228 Kit, following the manufacturer's protocol (Qiagen Sciences, Germantown, MD). Sex was

229 determined using a PCR assay [71]. Copy number at the Almond locus was estimated using a

230 custom TaqMan Copy Number Assay (ThermoFisher Scientific, Waltham, MA) targeted to an

231 intron in Mlana (MLANA_CCWR201), and an intron in RNaseP was used for normalization.

232 TaqMan samples were run in quadruplicate according to manufacturer's protocol. Copy number

233 (CN) was determined using CopyCaller Software v2.1 (ThermoFisher Scientific, Waltham, MA).

234 Two separate plates of DNA samples were included in the TaqMan assay. The first plate

235 contained all but one sample used in this study. We also included DNA control samples from

236 adults that were confirmed by phenotype and genotype to be non-Almond ( 3 samples),

237 heterozygous Almond (2 samples), and hemizygous Almond (2 samples). Non-Almond

238 genotypes were called in our experimental samples when the calculated CN was less than 2.0.

239 Heterozygous and hemizygous Almond genotypes were called when $\mathrm{CN}$ was between 2.0 and

240 12.0, and the distinction between these genotypes was based on a PCR assay for sex

241 (hemizygous Almond if female, heterozygous Almond if male). The second assay plate 
242 contained only one experimental sample, KD710 NOV17\#04, plus Almond and non-Almond

243 controls (one of each). This plate yielded lower calculated CN results for heterozygous Almond

244 individuals, and thus genotype prediction results were adjusted accordingly (indicated with * in

245 S1 Table). Results for sex and copy number genotyping for all samples from both plates are

246 shown in S1 Table.

247

248

249 image analysis.

\section{Imaging of eye sections}

We did not obtain clear anterior and posterior landmarks together in the same histologic sections, so we used different sections to quantify anterior and posterior pigmentation for each eye. For pigmentation analyses of anterior structures, we selected 3 sections from each eye that included the approximate center of the lens. Images were taken of the iris pigmented epithelium, the ciliary body, and the ora serrata (for anterior RPE analysis). For pigmentation analyses of the posterior RPE, we selected 2-3 sections containing the optic nerve, and images were taken of the RPE on both sides adjacent to the optic nerve. Sections were imaged using a Nikon Ti-E inverted microscope (Nikon Instruments Inc, Melville, NY) with a high-sensitivity Andor Zyla sCMOS camera (Oxford Instruments, Abingdon, Oxon, United Kingdom) and LED light source. For the IPE, anterior RPE, and posterior RPE images were taken using 100x magnification, and Z-stacks of each section were taken using $0.02-\mu \mathrm{m}$ steps through the tissue layers containing pigmented melanosomes using Nikon NIS-Elements software. For the ciliary body, images were taken on the same microscope using 20x magnification and $0.2 \mu \mathrm{m}$ steps. Stacks were merged to create an Extended Depth of Focus (EDF) file. EDF files were then exported to create a TIFF file for 


\section{Image analysis}

TIFF images were imported into Adobe Photoshop (Adobe Inc., San Jose, California).

268 For each image, the IPE or RPE structure was selected and the background (non-IPE or non-RPE

269 tissues) was deleted. For the ciliary body, area for analysis was determined by cropping regions

270 that contained pigmented melanosomes or reflective structures that are smaller than a single cell,

271 which include melanosomes and pre-melanosomes. The cropped images were imported into

272 ImageJ (imagej.nih.gov/) and the threshold command was used to determine \%-pigmented area

273 for each structure. Optimal thresholding values for pigmented area were determined visually in

274 ImageJ using non-Almond samples for reference, to find values that include the most

275 melanosomes possible, without picking up background pixels (0-100 for the 100x images of IPE

276 or RPE layer, and 0-120 for the 20x images of the ciliary body). Thresholding values for total

277 area were determined visually to include the total area of the cropped regions $(0-220$ for the $100 \mathrm{x}$

278 images of the IPE and RPE, and 0-240 for the 20x images of the ciliary body). The \%-pigmented

279 area for each structure was determined by dividing the pigmented area by the total area. See S2

280 Table for raw data.

\section{Acknowledgements}

We thank the Cell Imaging Core at the University of Utah for use of microscopy

284 equipment and software; Michael J. Bridge for assistance and advice on imaging; Kristen Kwan

285 for discussions of eye development; Anna Vickrey for assistance with thresholding analysis and

286 comments on the manuscript; and Emily Maclary and Elena Boer for comments on the

287 manuscript. This work was supported by NSF fellowship GRF 1256065 to R.B. and NIH grant 
288 R35 GM131787 to M.D.S. The funders had no role in study design, data collection and analysis,

289 decision to publish, or preparation of the manuscript.

\section{References}

291 1. Brooks BP, Larson DM, Chan C-C, et al. (2007) Analysis of ocular hypopigmentation in

$292 \quad \mathrm{rab38} \mathrm{cht} / \mathrm{cht}$ mice. Investigative Opthalmology \& Visual Science 48:3905.

293 doi:10.1167/iovs.06-1464.

294 2. Bellone RR. (2010) Pleiotropic effects of pigmentation genes in horses. Animal Genetics

295 41:100-110. doi:10.1111/j.1365-2052.2010.02116.x.

296 3. Reissmann M, Ludwig A. (2013) Pleiotropic effects of coat colour-associated mutations in

297 humans, mice and other mammals. Seminars in Cell and Developmental Biology 24:576-

298 586. doi:10.1016/j.semcdb.2013.03.014.

299 4. Gronskov K, Ek J, Brondum-Nielsen K. (2007) Oculocutaneous albinism. Orphanet

$300 \quad$ Journal of Rare Diseases 2:43. doi:10.1186/1750-1172-2-43.

301 5. Boissy RE, Zhao H, Oetting WS, et al. (1996) Mutation in and lack of expression of 302 tyrosinase-related protein-1 (TRP-1) in melanocytes from an individual with brown 303 oculocutaneous albinism: a new subtype of albinism classified as "OCA3." American $304 \quad$ Journal of Human Genetics 58:1145-56.

305 6. Seiji M, Fitzpatrick TB, Birbeck MS. (1961) The melanosome: a distinctive subcellular 306 particle of mammalian melanocytes and the site of melanogenesis. The Journal of 307 Investigative Dermatology 36:243-252. doi:10.1038/jid.1961.42. 
308 7. Bharti K, Nguyen MTT, Skuntz S, Bertuzzi S, Arnheiter H. (2006) The other pigment

309 cell: Specification and development of the pigmented epithelium of the vertebrate eye.

310 Pigment Cell Research 19:380-394. doi:10.1111/j.1600-0749.2006.00318.x.

311 8. Tomita Y, Takeda A, Okinaga S, Tagami H, Shibahara S. (1989) Human oculocutaneous

312 albinism caused by single base insertion in the tyrosinase gene. Biochemical and

313 Biophysical Research Communications 164:990-996. doi:10.1016/0006-291X(89)91767-

$314 \quad 1$.

315 9. Puri N, Gardner JM, Brilliant MH. (2000) Aberrant pH of Melanosomes in Pink-Eyed

316 Dilution (p) Mutant Melanocytes. Journal of Investigative Dermatology 115:607-613.

317 doi:10.1046/J.1523-1747.2000.00108.X.

318 10. Rinchik EM, Bultman SJ, Horsthemke B, Lee S-T, Strunk KM, Spritz RA, Avidano KM, 319 Jong MTC, Nicholls RD. (1993) A gene for the mouse pink-eyed dilution locus and for 320 human type II oculocutaneous albinism. Nature 361:72-76. doi:10.1038/361072a0.

321 11. Newton JM, Cohen-Barak O, Hagiwara N, Gardner JM, Davisson MT, King RA, Brilliant MH. (2001) Mutations in the Human Orthologue of the Mouse underwhite Gene (uw) Underlie a New Form of Oculocutaneous Albinism, OCA4. The American Journal of Human Genetics 69:981-988. doi:10.1086/324340.

325 12. Fukamachi S, Shimada A, Shima A. (2001) Mutations in the gene encoding B, a novel 326 transporter protein, reduce melanin content in medaka. Nature Genetics 28:381-385. 327 doi:10.1038/ng584.

328 13. Vogel P, Read RW, Vance RB, Platt KA, Troughton K, Rice DS. (2008) Ocular albinism 
and hypopigmentation defects in Slc24a5-/- mice. Veterinary Pathology 45:264-279. doi:10.1354/vp.45-2-264.

331 14. Lamason R, MA M, JR M, et al. (2005) SLC24A5, a putative cation exchanger, affects pigmentation in zebrafish and humans. Science 310:1782-6.

333 15. Brilliant MH. (2001) The mouse $\mathrm{p}$ (pink-eyed dilution) and human P genes,

334 oculocutaneous albinism type 2 (OCA2), and melanosomal pH. Pigment Cell Research 14:86-93. doi:10.1034/j.1600-0749.2001.140203.x.

16. Gelatt KN, Powell NG, Huston K. (1981) Inheritance of microphthalmia with coloboma in the Australian shepherd dog. American Journal of Veterinary Research 42:1686-1690.

18. Cichorek M, Wachulska M, Stasiewicz A, Tymińska A. (2013) Skin melanocytes: doi:10.5114/pdia.2013.33376.

345 19. Sulaimon SS, Kitchell BE. (2003) The biology of melanocytes. Veterinary Dermatology 14:57-65. doi:10.1046/j.1365-3164.2003.00327.x.

347 20. Arnheiter H, Hou L, Nguyen M-TT, Bismuth K, Csermely T, Murakami H, Skuntz S, Liu 
349 21. Dupin E, Le Douarin NM. (2003) Development of melanocyte precursors from the

350 vertebrate neural crest. Oncogene 22:3016-3023. doi:10.1038/sj.onc.1206460.

351 22. Bishop PN, Takanosu M, le Goff M, Mayne R. (2002) The role of the posterior ciliary

352 body in the biosynthesis of vitreous humour. Eye 16:454-460.

353

doi:10.1038/sj.eye. 6700199 .

23. Thumann G. (2001) Development and cellular functions of the iris pigment epithelium. Survey of Ophthalmology 45:345-354. doi:10.1016/S0039-6257(00)00195-8.

24. Steinberg RH. (1985) Interactions between the retinal pigment epithelium and the neural retina. Documenta Ophthalmologica 60:327-46.

25. Karlsson AC, Kerje S, Hallböök F, Jensen P. (2009) The Dominant white mutation in the PMEL17 gene does not cause visual impairment in chickens. Veterinary Ophthalmology 12:292-298. doi:10.1111/j.1463-5224.2009.00714.x.

361 26. Bharti K, Liu W, Csermely T, Bertuzzi S, Arnheiter H. (2008) Alternative promoter use in 362 eye development: The complex role and regulation of the transcription factor MITF.

363 Development 135:1169-1178. doi:10.1242/dev.014142.

364 27. Cieslak M, Reissmann M, Hofreiter M, Ludwig A. (2011) Colours of domestication.

365 Biological Reviews 86:885-899. doi:10.1111/j.1469-185X.2011.00177.x.

366 28. Wriedt C, Christie W. (1925) Zur genetik der gesprenkelten haustaube. Induktive 367 Abstammungs- und Vererbungslehre 38:271-306. doi:10.1007/BF02118234. 
40.

370 30. Hollander WF. (1944) Mosaic Effects in Domestic Birds. The Quarterly Review of

$371 \quad$ Biology 19:285-307.

372 31. National Pigeon Association Research Committee. (1951) N.P.A. Information Booklet \#1:

373 Project on Genetics. Ink Spot Inc., Burrton, Kansas.

374 32. Levi WM. (1945) The Pigeon (Second Revised Edition). Levi Publishing Co., Sumter, SC

375 33. Hollander WF. (1982) Origins and excursions in pigeon genetics- flecks and sex. The Ink

376 Spot INC, Burton, Kansas.

377 34. Hollander WF. (1942) Auto-sexing in the domestic pigeon. Journal of Heredity 33:135-

378 140. doi:10.1093/oxfordjournals.jhered.a105150.

379 35. Sell A. (2012) Pigeon genetics: applied genetics in the domestic pigeon. Sell Publishing,

$380 \quad$ Achim, Germany.

381 36. Bruders R, Van Hollebeke H, Osborne EJ, Kronenberg Z, Maclary E, Yandell M, Shapiro 382 MD. (2020) A copy number variant is associated with a spectrum of pigmentation patterns 383 in the rock pigeon (Columba livia). PLOS Genetics 16:e1008274. doi:10.1371/journal.pgen.1008274.

385 37. Mazie AM De, Donselaar E Van, Salvi S, Davoust J, Cerottini J, Slot JW. (2002) The 386 melanocytic protein Melan-A / MART-1 has a subcellular localization distinct from $387 \quad$ typical melanosomal proteins. Traffic 3:678-693.

388 38. Hoashi T, Watabe H, Muller J, Yamaguchi Y, Vieira WD, Hearing VJ. (2005) MART-1 is 
required for the function of the melanosomal matrix protein PMEL17/GP100 and the maturation of melanosomes. Journal of Biological Chemistry 280:14006-14016. doi:10.1074/jbc.M413692200.

392

393

39. Ramsey, Ewart, Render, Cook, Latimer. (1999) Congenital ocular abnormalities of Rocky Mountain Horses. Veterinary Ophthalmology 2:47-59. doi:10.1046/j.14635224.1999.00050.x.

40. Hellström AR, Watt B, Fard SS, et al. (2011) Inactivation of PMEL alters melanosome shape but has only a subtle effect on visible pigmentation. PLoS Genetics 7:e1002285. doi:10.1371/journal.pgen.1002285.

41. Kerje S, Sharma P, Gunnarsson U, et al. (2004) The Dominant white, Dun and Smoky color variants in chicken are associated with insertion/deletion polymorphisms in the PMEL17 gene. Genetics 168:1507-1518. doi:10.1534/genetics.104.027995.

42. Schmutz SM, Dreger DL. (2013) Interaction of MC1R and PMEL alleles on solid coat colors in Highland cattle. Animal Genetics 44:9-13. doi:10.1111/j.13652052.2012.02361.x.

43. Clark LA, Wahl JM, Rees CA, Murphy KE. (2006) Retrotransposon insertion in SILV is responsible for merle patterning of the domestic dog. PNAS 103:1376-81. doi:10.1073/pnas.0506940103.

44. Murphy SC, Evans JM, Tsai KL, Clark LA. (2018) Length variations within the Merle retrotransposon of canine PMEL: Correlating genotype with phenotype. Mobile DNA 9:26. doi:10.1186/s13100-018-0131-6. 
45. Ballif BC, Ramirez CJ, Carl CR, Sundin K, Krug M, Zahand A, Shaffer LG, Flores-Smith H. (2018) The PMEL gene and Merle in the domestic dog: a continuum of insertion lengths leads to a spectrum of coat color variations in australian shepherds and related

414 46. Gelatt KN, McGill LD. (1973) Clinical characteristics of microphthalmia with colobomas of the Australian Shepherd Dog. Journal of the American Veterinary Medical Association $162: 393-6$.

47. Brunberg E, Andersson L, Cothran G, Sandberg K, Mikko S, Lindgren G. (2006) A missense mutation in PMEL17 is associated with the Silver coat color in the horse. BMC Genetics 7:46. doi:10.1186/1471-2156-7-46. cases. Veterinary Ophthalmology 14:313-320. doi:10.1111/j.1463-5224.2011.00878.x.

49. Kaps BM. (2010) Multiple congenital ocular abnormalities (MCOA) in Rocky Mountain Horses and Kentucky Mountain Saddle Horses in Europe. Pferdeheilkunde 26:536-540.

50. Imamura M, Takahashi A, Yamauchi T, et al. (2016) Genome-wide association studies in the Japanese population identify seven novel loci for type 2 diabetes. Nature Communications 7:10531. doi:10.1038/ncomms10531.

428 51. Hara K, Fujita H, Johnson TA, et al. (2014) Genome-wide association study identifies three novel loci for type 2 diabetes. Human Molecular Genetics 23:239-246. doi:10.1093/hmg/ddt399. 
431 52. Williams Amy AL, Jacobs Suzanne SBR, Moreno-Macías H, et al. (2014) Sequence

432 variants in SLC16A11 are a common risk factor for type 2 diabetes in Mexico. Nature

$433 \quad 506: 97-101$. doi:10.1038/nature12828.

434 53. Halestrap AP. (2012) The monocarboxylate transporter family-structure and functional 435 characterization. IUBMB Life 64:1-9. doi:10.1002/iub.573.

436 54. Meredith D, Christian HC. (2008) The SLC16 monocaboxylate transporter family. Xenobiotica 38:1072-1106. doi:10.1080/00498250802010868.

438 55. Halestrap AP, Meredith D. (2004) The SLC16 gene family - From monocarboxylate 439 transporters (MCTs) to aromatic amino acid transporters and beyond. Pflugers Archiv 440 European Journal of Physiology 447:619-628. doi:10.1007/s00424-003-1067-2.

441 56. Cvekl A, Tamm ER. (2004) Anterior eye development and ocular mesenchyme: New 442 insights from mouse models and human diseases. BioEssays 26:374-386. doi:10.1002/bies.20009.

444 57. Gage PJ, Qian M, Wu D, Rosenberg KI. (2008) The canonical Wnt signaling antagonist DKK2 is an essential effector of PITX2 function during normal eye development. Developmental Biology 317:310-324. doi:10.1016/j.ydbio.2008.02.030.

447 58. Johnston MC, Noden DM, Hazelton RD, Coulombre JL, Coulombre AJ. (1979) Origins of avian ocular and periocular tissues. Experimental Eye Research 29:27-43. doi:10.1016/0014-4835(79)90164-7. 
in the development of the anterior segment in the eye. Developmental Dynamics 238:2149-2162. doi:10.1002/dvdy.22033.

60. Lahola-Chomiak AA, Footz T, Nguyen-Phuoc K, et al. (2019) Non-Synonymous variants in premelanosome protein (PMEL) cause ocular pigment dispersion and pigmentary glaucoma. Human Molecular Genetics 28:1298-1311. doi:10.1093/hmg/ddy429.

61. Niyadurupola N, Broadway DC. (2008) Pigment dispersion syndrome and pigmentary glaucoma - A major review. Clinical and Experimental Ophthalmology 36:868-882. doi:10.1111/j.1442-9071.2009.01920.x.

62. Lee ZH, Hou L, Moellmann G, Kuklinska E, Antol K, Fraser M, Halaban R, Kwon BS. (1996) Characterization and subcellular localization of human Pmel 17/silver, a 100-kDa (pre)melanosomal membrane protein associated with 5,6,-Dihydroxyindole-2-Carboxylic Acid (DHICA) converting activity. Journal of Investigative Dermatology 106:605-610.

63. Schonthaler HB, Lampert JM, von Lintig J, Schwarz H, Geisler R, Neuhauss SCFF. (2005) A mutation in the silver gene leads to defects in melanosome biogenesis and doi:10.1111/1523-1747.EP12345163.

64. Lamason RL, Mohideen MAPK, Mest JR, et al. (2005) SLC24A5, a putative cation exchanger, affects pigmentation in zebrafish and humans. Science 310:1782-1786. doi:10.1126/science.1116238.

471 65. Kobayashisj T, Urabel K, Orlown SJ, Higashil K, Imokawao G, Kwonll BS, Potterfy B, 
Hearing VJ. (1994) The Pmel17/Silver locus protein. The Journal of Biological Chemistry 269:2919-29205.

66. Berson JF, Harper DC, Tenza D, Raposo G, Marks MS. (2001) Pmel17 initiates

475 premelanosome morphogenesis within multivesicular bodies. Molecular Biology of the Cell 12:3451-64. doi:10.1091/mbc.12.11.3451.

67. Quinn JW. (1971) The Pigeon Breeders Notebook An Introduction to Pigeon Science. Published by Author, Atwater, Ohio.

68. Brunberg E, Andersson L, Cothran G, Sandberg K, Mikko S, Lindgren G. (2006) A missense mutation in PMEL17 is associated with the Silver coat color in the horse. BMC Genetics 7:46. doi:10.1186/1471-2156-7-46.

69. Ségard EM, Depecker MC, Lang J, Gemperli A, Cadoré J-L. (2013) Ultrasonographic features of PMEL17 (Silver) mutant gene-associated multiple congenital ocular anomalies

70. Sponenberg DP. (1984) Germinal reversion of the merle allele in Australian shepherd 435. doi:10.1111/vop.12021. of non-ratite birds. Journal of Avian Biology 30:116. doi:10.2307/3677252.

72. Institute NC. Line drawing showing lateral view of the eye. https://visualsonline.cancer.gov/details.cfm?imageid=1767. 
bioRxiv preprint doi: https://doi.org/10.1101/2020.10.17.339655; this version posted October 17, 2020. The copyright holder for this preprint (which was not certified by peer review) is the author/funder, who has granted bioRxiv a license to display the preprint in perpetuity. It is made available under aCC-BY-NC 4.0 International license.

492

73. Eroschenko VP. (2004) Di Fiores Atlas of Histology: With Functional Correlations, 9th

493 ed. Lippincott Williams and Wilkins.

494 


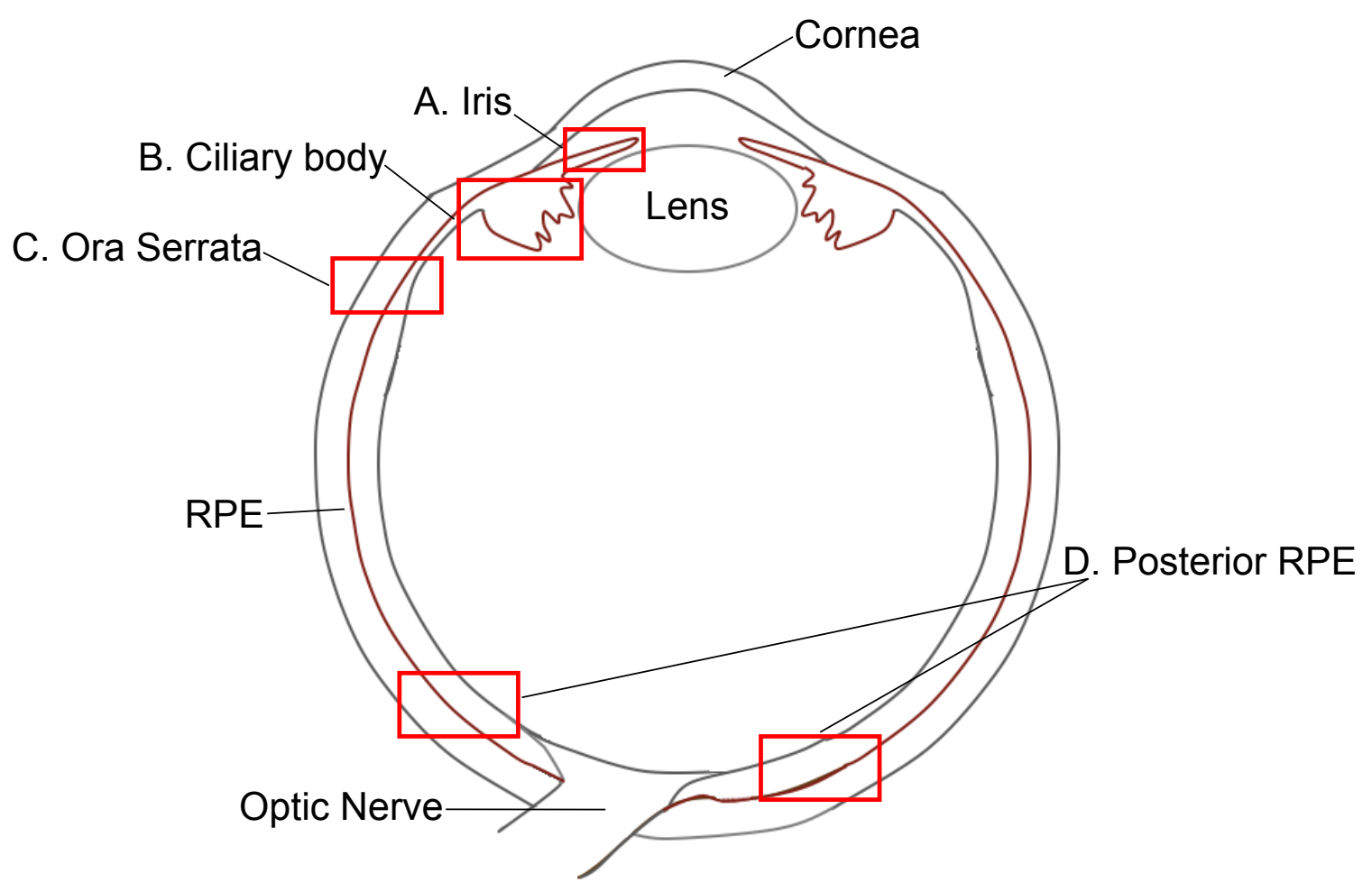

Figure 1. Simplified schematic of an eye in transverse section. Anterior is at the top, posterior at the bottom. Each region of the eye that was analyzed for pigmentation is labeled as follows: (A), Iris; (B), Ciliary body; (C), Ora serrata; (D), Posterior RPE. Red boxes represent approximate locations of regions that were imaged and analyzed (not to scale). Brown lines represent pigmented cell layers of the eye. RPE, retinal pigment epithelium. Schematic based on [72, 73]. 

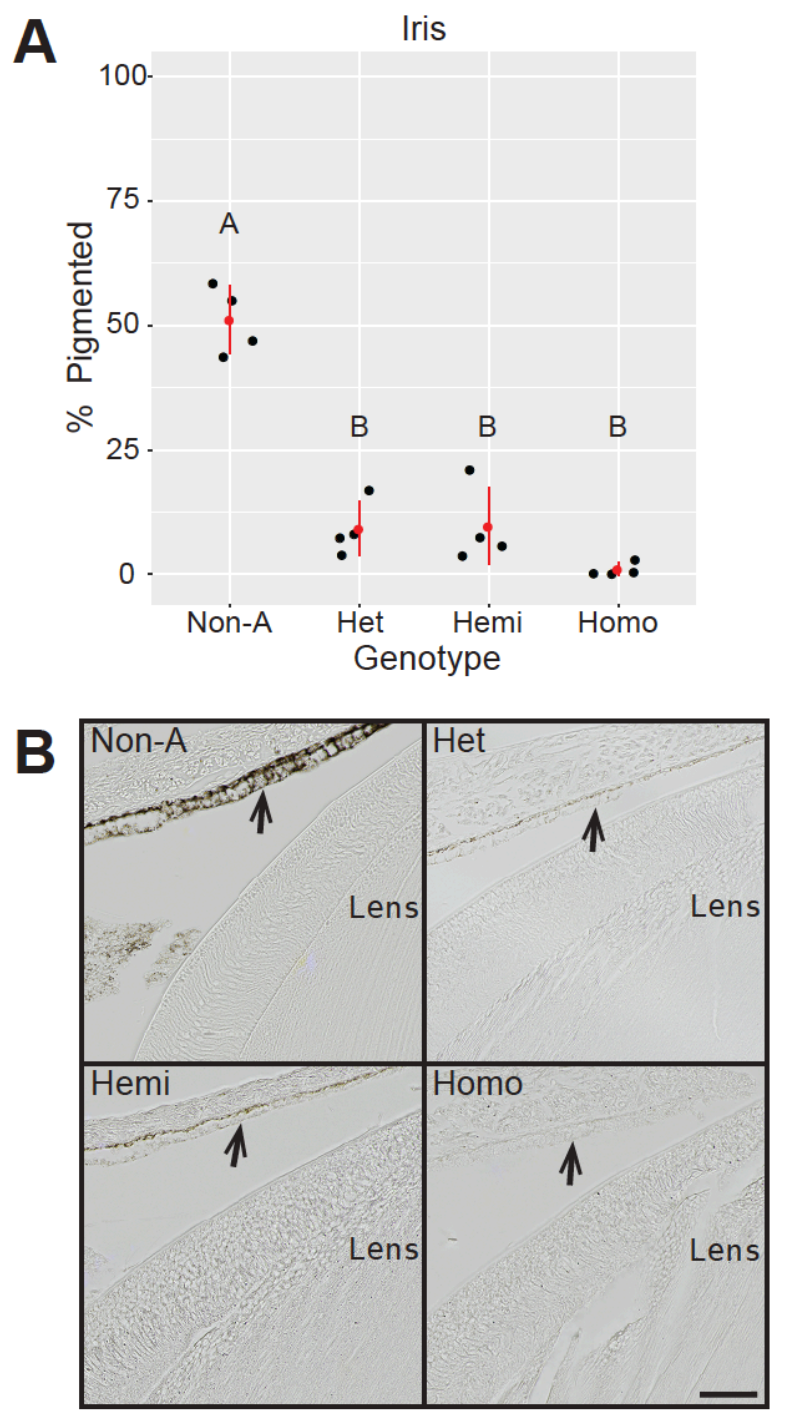

Figure 2. Iris pigmentation is reduced in all Almond genotypes.

(A) Percentage of the IPE that is pigmented in different genotypes. Four hatchling eyes were analyzed per genotype. 3 sections were analyzed for each eye, and mean values are plotted as black dots. Red dot and line show mean and standard deviation, respectively. Different letters indicate groups with statistically significant differences in gene expression determined by Anova and post-hoc Tukey $(\mathrm{p}<0.05)$. Genotypes: Non-A, non-Almond; Het, heterozygous Almond; Hemi, hemizygous Almond; Homo, homozygous Almond. (B) Representative images of the IPE for each genotype. Arrows point to the pigmented layer of the IPE. Pigmentation is reduced in heterozygous and hemizygous Almond hatchlings and is very faint in homozygous Almond hatchling eyes. Scale bar in bottom right image is $50 \mu \mathrm{m}$. 

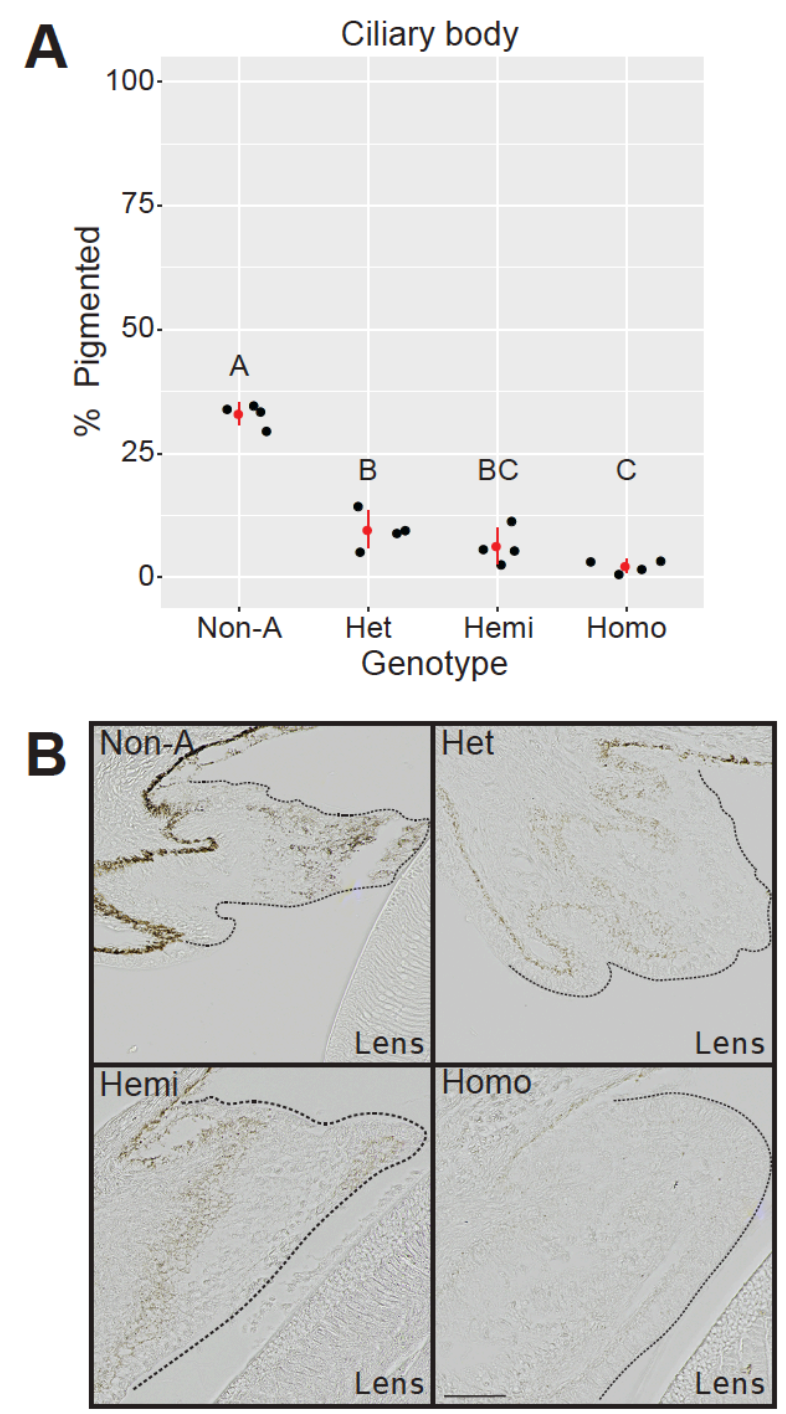

516 Figure 3. Ciliary body pigmentation is reduced in all Almond genotypes.

517 (A) Percentage of the ciliary body that is pigmented in different genotypes. Four hatchling eyes

518 were analyzed per genotype. 3 sections were analyzed for each eye, and mean values are plotted 519 as black dots. Red dot and line show mean and standard deviation, respectively. Different letters indicate groups with statistically significant differences in gene expression determined by Anova and post-hoc Tukey $(\mathrm{p}<0.05)$. Genotypes: Non-A, non-Almond; Het, heterozygous Almond;

522 Hemi, hemizygous Almond; Homo, homozygous Almond. (B) Representative images of the ciliary body (outlined with dotted line) for each genotype. Pigmentation is reduced in heterozygous and hemizygous Almond hatchlings and is very faint in homozygous Almond hatchling eyes. Scale bar in bottom right image is $50 \mu \mathrm{m}$. 

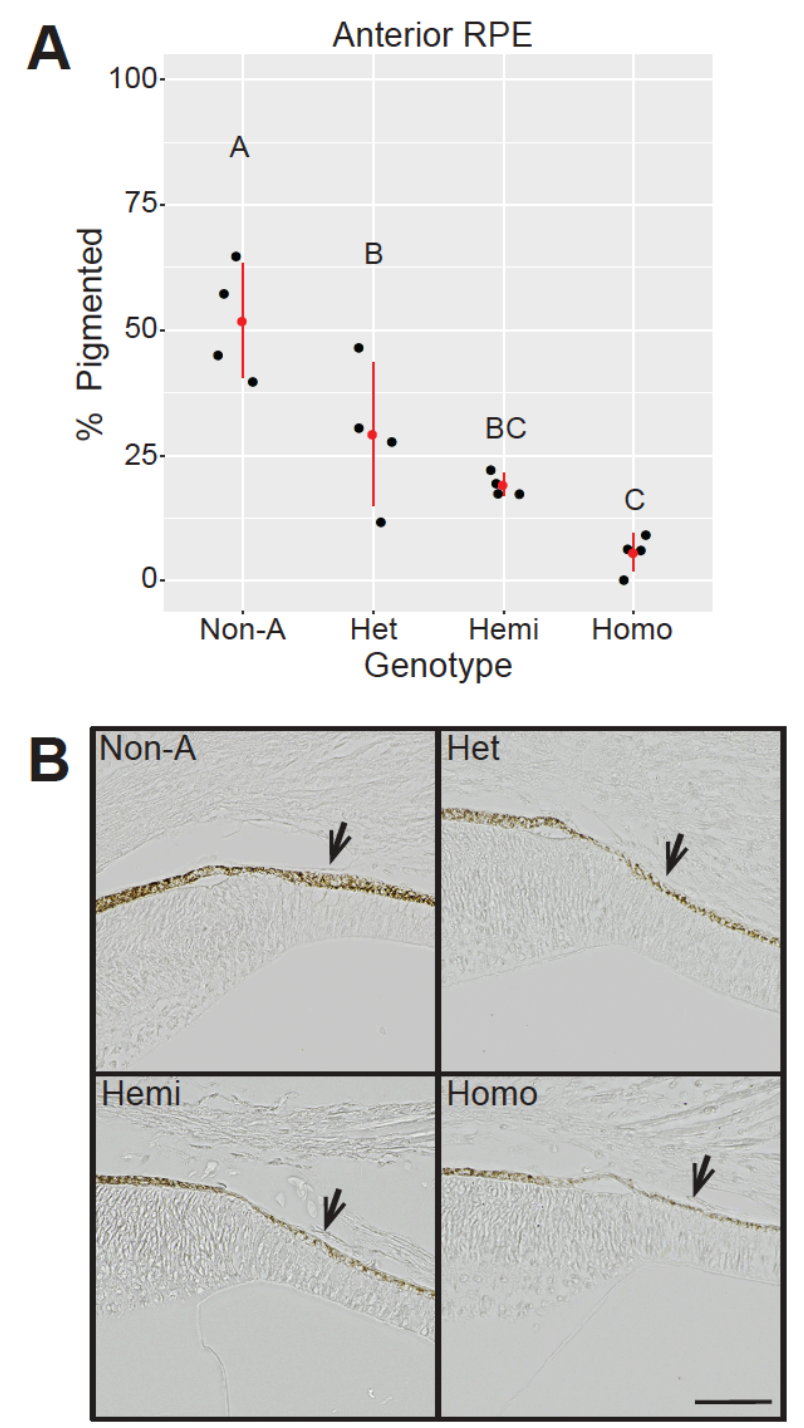

Figure 4. Anterior RPE pigmentation is reduced in all Almond genotypes. were analyzed per genotype. Three sections were analyzed for each eye, and mean values are plotted as black dots. Red dot and line show mean and standard deviation, respectively. Different letters indicate groups with statistically significant differences in gene expression determined by Anova and post-hoc Tukey $(\mathrm{p}<0.05)$. Genotypes: Non-A, non-Almond; Het, heterozygous Almond; Hemi, hemizygous Almond; Homo, homozygous Almond. (B) Representative images of the RPE for each genotype. Arrows point to the pigmented layer of the RPE. Pigmentation is reduced in all Almond genotypes. Scale bar in bottom right image is $50 \mu \mathrm{m}$. 

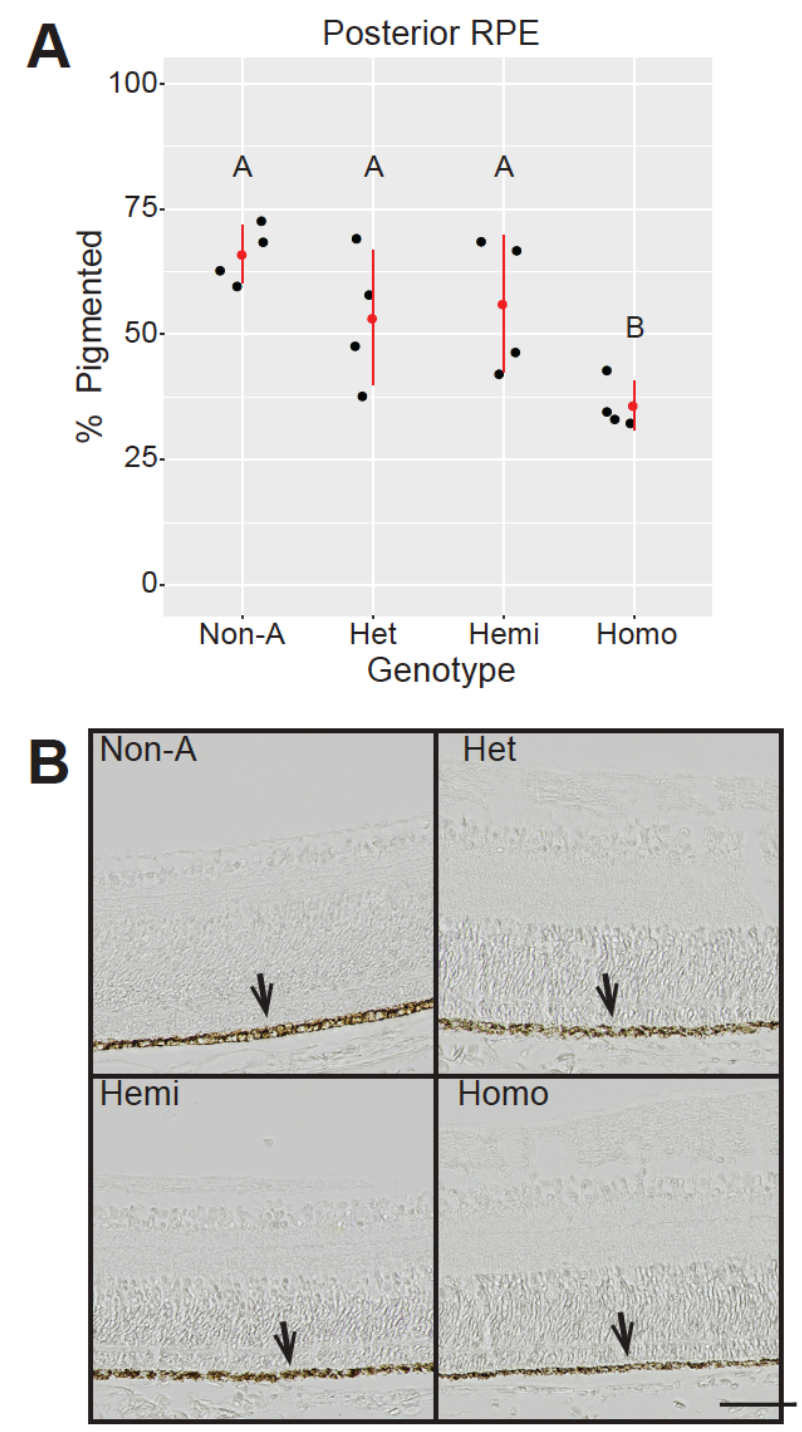

Figure 5. Posterior RPE pigmentation is less affected than anterior pigmentation in eyes of Almond pigeons.

539 (A) Percentage of the RPE that is pigmented in different genotypes. Four hatchling eyes were analyzed per genotype. 2-3 sections were analyzed for each eye, and mean values are plotted as black dots. Red dot and line show mean and standard deviation, respectively. Different letters indicate groups with statistically significant differences in gene expression determined by Anova and post-hoc Tukey $(\mathrm{p}<0.05)$. Genotypes: Non-A, non-Almond; Het, heterozygous Almond; Hemi, hemizygous Almond; Homo, homozygous Almond. (B) Representative images of the RPE for each of genotype. Arrows point to the pigmented layer of the RPE. Pigmentation is only

546 slightly reduced in heterozygous Almond hatchling eyes. Scale bar in bottom right image is 50

$547 \mu \mathrm{m}$. 